\title{
Tuberculosis in Scottish military veterans: evidence from a retrospective cohort study of 57000 veterans and 173000 matched non-veterans
}

\author{
Beverly P Bergman, DF Mackay, JP Pell
}

Institute of Health and Wellbeing, University of Glasgow, Glasgow, UK

\section{Correspondence to} Dr Beverly P Bergman, Institute of Health and Wellbeing, Public Health and Health Policy, 1 Lilybank Gardens, Glasgow G12 8RZ, UK; b. bergman.1@research.gla.ac.uk

Received 18 December 2015 Revised 22 January 2016 Accepted 17 February 2016 Published Online First 22 March 2016

\section{CrossMark}

\footnotetext{
To cite: Bergman $B P$, Mackay DF, Pell JP. J R Army Med Corps 2017;163:5357.
}

\begin{abstract}
Objective Tuberculosis was a major cause of morbidity and manpower loss in the Armed Forces during World War II. Military control programmes commenced in the 1950s but were initially limited in scope by the many recruits who were already tuberculin positive on enlistment. The aim of our study was to examine whether veterans have an increased risk of tuberculosis compared with non-veterans.
\end{abstract}

Methods Retrospective cohort study of 57000 veterans born 1945-1985, and 173000 people with no record of military service, resident in Scotland, matched for age, sex and area of residence, using Cox proportional hazard analysis to compare the risk of tuberculosis overall, by birth cohort, length of service and year of diagnosis and to examine comorbidities.

Results Over mean 29 years follow-up, 69 (0.12\%) veterans were recorded as having tuberculosis, compared with $267(0.15 \%)$ non-veterans (unadjusted HR 0.90, $95 \% \mathrm{Cls} 0.69$ to $1.19, \mathrm{p}=0.463$ ). Only the $1945-1949$ veterans' birth cohort was at higher risk, unadjusted HR $1.54,95 \%$ Cls 0.98 to $2.45, p=0.061$, although the difference in risk did not achieve significance. Veterans born from 1950 were at significantly reduced risk of tuberculosis compared with non-veterans after adjusting for deprivation, $H R \quad 0.67,95 \% \mathrm{Cl} 0.47$ to 0.95 , $\mathrm{p}=0.026$. The most common comorbidities were smoking-related and alcohol-related disease. The risk of comorbid hepatitis B or C was very low, in both veterans and non-veterans. No length of service was associated with an increased risk of tuberculosis in comparison with non-veterans.

Conclusions Scottish veterans born before 1950 are at moderately increased risk of tuberculosis compared with age, sex and geographically matched civilians with no record of service, although the difference is not statistically significant. Scottish veterans born from 1950 show a reduction in risk compared with civilians. Tuberculosis should be considered in the differential diagnosis of respiratory disease in the older veteran.

\section{INTRODUCTION}

During the 19th century, tuberculosis was the leading cause of death and disability in the UK, although the overall number of deaths fell in the second half of the 19th and early 20th centuries. ${ }^{1}$ Between 1952 and 1985, the incidence of tuberculosis reduced in the general US population, before starting to increase again. ${ }^{2}$ In the UK, cases rose by 46\% between 1998 and 2009, with much of the increase arising in people born in countries having a high burden of tuberculosis ${ }^{3}$ and are now

\section{Key messages}

Tuberculosis is known to have been a major cause of morbidity among military personnel during World War II and earlier.

- Scottish veterans born before 1950 are at moderately increased risk of tuberculosis compared with non-veterans.

- Veterans born from 1950 are at lower risk of tuberculosis than non-veterans, providing evidence for the effectiveness of military control measures.

- Tuberculosis should be considered in the differential diagnosis of respiratory disease in the older veteran.

deemed unacceptably high, at 12.3 per 100000 in 2013, compared with other countries. ${ }^{4}$ Among UK-born people, the incidence is around four cases per 100000 people per year, compared with 70 per 100000 in people born in high-risk areas overseas. ${ }^{3}{ }^{4}$ Other risk factors for tuberculosis include smoking, heavy alcohol use, poverty and homelessness, as well as immunosuppression, especially in consequence of diseases such as HIV. ${ }^{2}$ Diabetes is also an independent risk factor, ${ }^{5}$ and may account for some of the recent increase in incidence.

Military personnel may be at increased risk of tuberculosis as a result of shared accommodation, ${ }^{6}$ increased prevalence of smoking, ${ }^{7} 8$ alcohol consumption $^{9}$ or as a result of military service in highrisk areas. In the late 19th century, tuberculosis was a major cause of manpower loss, accounting for around $17 \%$ of medical discharges from the British Army in 1891 (300 per 100000 strength per year), and was the most common disease-related cause of discharge from service. Although the rate fell to an average of 150 per 100000 during the early 20th century with improvements in public health, it continued at around the same level until the 1950s. ${ }^{10}$ World War II saw a heavy burden of tuberculosis; between September 1939 and September 1951, 60645 individuals were discharged from the Armed Forces and awarded a pension for tuberculosis which was considered to have been either caused by or aggravated by war service. ${ }^{11}$ With the introduction of effective treatment and a control programme for tuberculosis in the Armed Forces, the rate of medical discharge fell throughout the late 1950s and 1960s, and by the end of the millennium, discharge for this reason had become 
rare. ${ }^{10}$ There have been a number of changes in Service immunisation policy to reflect changing national guidelines and risk assessment. Currently, all recruits from high incidence countries (defined as incidence $\geq 40$ per 100000 per year) are screened in accordance with UK national guidelines, ${ }^{12}$ while all others are offered Mantoux testing and, if necessary, BCG vaccine unless they have evidence of previous immunisation (either documentary or a BCG scar). Catch-up testing and immunisation is offered to deployable personnel under the age of 36 years who have not previously been immunised. ${ }^{13}$ This study examines the impact of tuberculosis in the current generation of military veterans, many of whom served prior to the full implementation of control measures.

\section{METHODS}

The Scottish Veterans Health Study is a retrospective cohort study comprising all 56570 military veterans (defined as individuals having at least one day's service in the UK Armed Forces ${ }^{14}$ ) born between 1945 and 1985 who were registered with NHS Scotland both prior to military service and following discharge, and a comparison group of 172753 individuals with no record of military service, matched by age, sex and postcode sector of residence (mean population 5000). Participants were identified via their electronic NHS registration records, which provided demographic information as well as the dates of entering and leaving military service. These records were linked, at the individual level, to routine hospital admissions data (Scottish Morbidity Record SMR01) and death certificates to provide follow-up information on incidence of tuberculosis, comorbidities and mortality. Information was available for follow-up events that occurred between 1 January 1981 and 31 December 2012 inclusive. The cohort and methods have been described in detail elsewhere. ${ }^{15}$ The data extract was pseudoanonymised, and approval for the study was granted by the Privacy Advisory Committee of the Information Services Division of NHS Scotland.

A measure of deprivation is available from the Scottish Index of Multiple Deprivation (SIMD), which is based on 6505 data zones, derived from postcode of residence, each having a mean population of 800 . Deprivation status is calculated from information on income, employment, health, education (including skills and training), housing, crime and access to services. ${ }^{16}$ The SIMD has been used to derive quintiles of socioeconomic status for the Scottish population; ranging from 1 (most deprived) to 5 (least deprived). The cohort participants were categorised according to these quintiles using postcode of residence.

Cox proportional hazard models were used to examine the association between veteran status and cumulative risk of tuberculosis, using age as the time dependent variable, age at first record of tuberculosis as the failure time and death (if no record of tuberculosis) as the censor time. The association with selected comorbidities in veterans and non-veterans with a diagnosis of tuberculosis was also examined. HRs and p values were calculated and the a priori rejection level was set at 0.05 . Proportionality was tested using methodology based on Schoenfeld residuals. ${ }^{17}$ The models were run univariately and then repeated adjusting for the confounding effect of deprivation. The analyses were repeated by year of birth, stratified in 5 -year bands, to examine birth cohort effects. Further subgroup analyses were undertaken to examine the effect of length of service, in categories reflecting common UK lengths of military engagement. Mortality in those with a diagnosis of tuberculosis was examined by cause. All analyses were performed using Stata V.12.1 and Excel 2007.

\section{RESULTS}

After data cleansing, 56205 (99.3\%) veterans and 172741 (99.9\%) non-veterans were included in the analysis. The mean period of follow-up was 29.3 years, and there was a total of 6.7 million person years of follow-up among veterans and nonveterans combined. During the period of follow-up, $69(0.12 \%)$ veterans had a diagnosis of tuberculosis compared with 267 $(0.15 \%)$ non-veterans. The reduction in risk in the veterans was not statistically significant in the unadjusted model, HR 0.90 , $95 \%$ CIs 0.69 to $1.19, p=0.463$. After adjusting for deprivation, the reduction in risk in veterans was greater but remained non-significant, HR $0.85,95 \%$ CI 0.65 to $1.12, p=0.247$. The Nelson-Aalen cumulative hazard plot confirmed the lower risk in veterans, using a landmark age of 20 years to exclude those with a history of childhood tuberculosis which may have precluded military service (Figure 1).

When analysed by birth cohort, only veterans born between 1945 and 1949 showed an increased risk of tuberculosis (Figure 2), although this was non-significant in the unadjusted model, HR $1.54,95 \%$ CI 0.98 to $2.45, \mathrm{p}=0.061$, and remained non-significant after adjusting for deprivation. Veterans in each of the more recent birth cohorts, 1950 onwards, were at lower or similar risk of tuberculosis compared with non-veterans; the overall reduction in risk in veterans born from 1950 was statistically significant after adjusting for deprivation, HR $0.67,95 \%$ CI 0.47 to $0.95, \mathrm{p}=0.026$.

Common comorbidities included alcoholic liver disease, affecting seven $(10.1 \%)$ of the veterans and 25 (9.4\%) of the non-veterans with tuberculosis; chronic obstructive pulmonary disease, affecting 19 (27.5\%) veterans and 52 (19.5\%) nonveterans; lung cancer, recorded in five $(7.2 \%)$ veterans and four $(1.5 \%)$ non-veterans and any mental health disorder, affecting eight $(11.6 \%)$ veterans with tuberculosis and 28 (10.5\%) nonveterans. Only for lung cancer did the difference in risk achieve statistical significance, OR 4.83, 95\% CI 1.33 to 17.95 , $\mathrm{p}=0.008$. The number of either veterans or non-veterans with tuberculosis who had a diagnosis of either hepatitis B or hepatitis $\mathrm{C}$ was very low. Five (7.2\%) veterans and 18 (6.7\%) nonveterans also had a recorded diagnosis of diabetes.

Analysis of year of first record of tuberculosis, using a kernel density plot (Figure 3) showed a gradual increase in cases throughout the 1980s and 1990s, reaching a peak around the year 2000 for both veterans and non-veterans, before starting to fall. There was a biphasic pattern, with a small peak in the

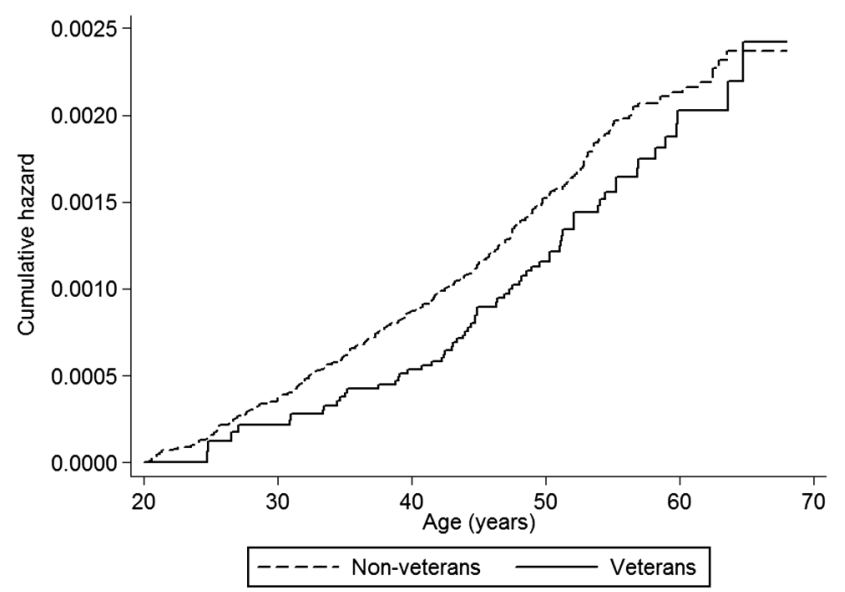

Figure 1 Nelson-Aalen cumulative hazard plot of tuberculosis in veterans and non-veterans. Landmark age 20 years. 


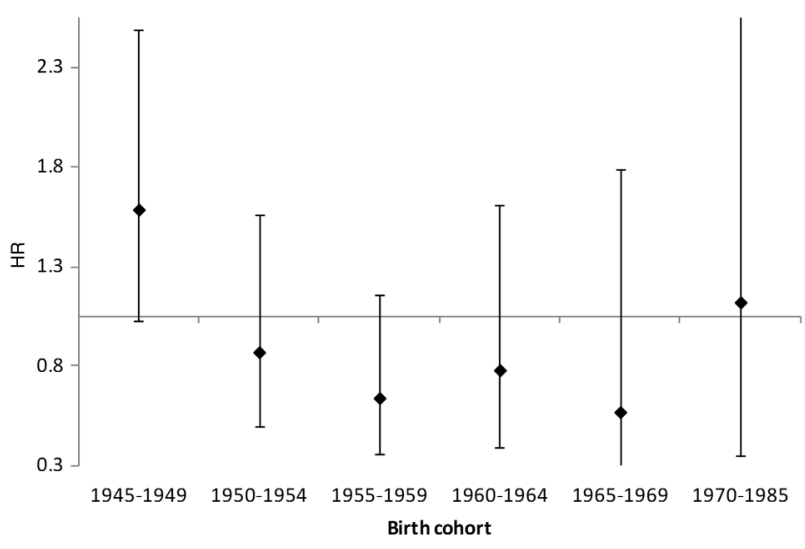

Figure 2 HRs for tuberculosis by birth cohort. Veterans referent to non-veterans.

mid-1980s, in both veterans and non-veterans although that peak was higher in the non-veterans.

Analysis by length of service showed that longer service was associated with the lowest risk of tuberculosis, but overall there was no increase in risk associated with any length of service, including Early Service Leavers, in comparison with the entire non-veteran group.

By the end of follow-up, 27 (39.1\%) veterans with tuberculosis had died, compared with 81 (30.3\%) non-veterans. Seven non-veterans with tuberculosis, but only one veteran, had a cause of death coded as alcohol dependence syndrome; no other cause of death predominated in either group.

\section{DISCUSSION}

\section{Main findings}

Evidence from the Scottish Veterans Health Study has demonstrated that the oldest veterans, born 1945-1949, were more likely to develop tuberculosis than people with no record of service matched for age, sex and area of residence, although the reverse was true for veterans born from 1950 onwards. Small numbers of cases precluded statistical significance at subgroup level, other than for all veterans born from 1950, where the reduction in risk was significant. Examination of comorbidities indicated that smoking and alcohol were risk factors for tuberculosis in both veterans and in non-veterans, but that the magnitude of association for smoking-related disease was higher in veterans. There was no evidence that drug abuse was a risk

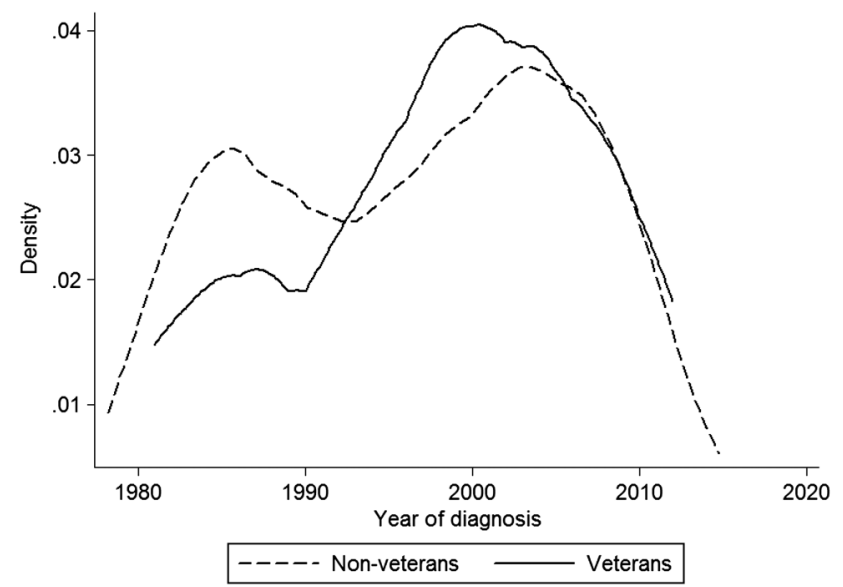

Figure 3 Kernel density plot of tuberculosis by year of first record of diagnosis. Veterans and non-veterans. factor, based on the finding of a lack of association with hepatitis B or C.

\section{Historical background}

In 1882, Robert Koch identified the causative organism for tuberculosis as Mycobacterium tuberculosis, and by 1921 human vaccination trials commenced using a vaccine based on an attenuated form of the related $M$. bovis, named Bacillus Calmette-Guérin (BCG) after the researchers who had developed it. ${ }^{18}$ Early vaccination programmes targeted infants but in 1953, the UK commenced routine administration of BCG vaccine to all tuberculin-negative 13 -year-old children whose parents consented. Because of the impact of tuberculosis in the Armed Forces and the risk of cross-infection in shared accommodation, a subcommittee of the Research Committee of the British Tuberculosis Association had been convened in November 1951 to consider the case for BCG vaccination of Service entrants. ${ }^{11}$ They identified important practical difficulties; $63.5 \%$ of 18 -year-olds were already tuberculin positive, and the rapid dispersal of recruits made it impractical to meet the timetable which would be required for tuberculin testing, reading and vaccination of 220000 men per year (150000 National Servicemen and 70000 regular recruits). The vaccine was also unstable and had to be administered within $48 \mathrm{~h}$ of receipt at a military establishment, presenting major logistic difficulties and a risk of wastage. ${ }^{19}$

Military BCG vaccination had already commenced covering certain categories of medical and nursing staff in $1951^{20}$ and Nepalese Gurkha soldiers in $1952 .^{21}$ A scheme for extending the programme to all recruits was proposed, linked to the mass miniature radiography (MMR) screening programme which by then was reaching $85 \%$ of all recruits (although the quality of some films gave rise to concern), noting that 50\%-60\% would be likely to prove tuberculin positive for some years to come. At that time it was generally considered that a positive tuberculin test indicated 'natural immunity', usually acquired through exposure to M. bovis in milk, but a Medical Research Council report in 1957 remarked, with evident surprise, that there was a high incidence of active tuberculosis developing within the subsequent two and a half years in those recruits with a tuberculin reaction in excess of $15 \mathrm{~mm}$, and suggested that it might be necessary to exclude such personnel from service. ${ }^{11}$ It was agreed that postvaccination retesting could be omitted as other evidence had been presented showing a high seroconversion rate. The Ministry of Labour and National Service considered that youths over 16 years of age were normally sufficiently mature to consent to testing and immunisation without the need for parental consent. The future impact of school-based immunisation was noted, with the proviso that it was not yet known whether immunity would wane. The slow development of immunity following BCG administration was also considered to present a case for the establishment of immunity prior to the commencement of service. The authors of the report recommended that both MMR screening and BCG vaccination were required in order to effect a substantial reduction in the incidence of tuberculosis in the Armed Forces, and that the two were complementary. They recommended a pilot scheme for a national BCG vaccination programme in Service recruits. Implementation of the scheme, together with routine chest radiography on entry and four yearly thereafter (the latter being discontinued in the early 1980s), and better treatment of active cases, resulted in a rapid fall in active military disease although latent disease persisted for some time. 
Factors contributing to high levels of tuberculosis in military personnel in earlier years included population mixing in a group which already had a high background prevalence, shared living accommodation, travel $\mathrm{l}^{22}$ and stress, ${ }^{23} 24$ all of which can contribute to cross-infection or reactivation of latent disease. Those living and working in a closely confined environment such as on board a warship were especially at risk. ${ }^{25}$ With the length of 'other rank' (non-commissioned) service ranging up to 22 years, or longer for those permitted to enter the Long Service list, and officers able to serve to age 55 years, there were still many people serving in the 1970s who had entered the Armed Forces prior to the introduction of the immunisation programme. They may have inadvertently acted as a reservoir of infection within the military community, many years prior to the recognition of the importance of, and ability to reliably diagnose, latent tuberculosis. Disease in these older military personnel is consistent with the findings of this study; those born in later years, who joined the Armed Forces after most of those who had entered service prior to the control programme had left, showed no greater risk than individuals who have never served. Published studies on the incidence or prevalence of tuberculosis in veterans are sparse but Levine reports an incidence of hospitalisation for tuberculosis 1.3 times higher in US veterans than in age-matched US males between 1984 and 1993 (29.1/100 000 compared with 22.1/100 000). ${ }^{26}$ However, the veterans were patients receiving care from Veterans Administration Medical Centres, access to which is limited to the lowest income group (11.3\% of veterans), who may have been at higher risk of tuberculosis for reasons other than their veteran status; the author notes comorbidity with AIDS (up to $\mathrm{r}=0.8, \mathrm{p}<0.001)$. In a major Australian study of mortality in Korean War veterans covering 50 years of observation, the standardised mortality ratio (SMR) for tuberculosis was 0.95 (95\% CI 0.40 to 1.49 ) after excluding unknowns but this was based on only 12 deaths (out of a total of 7514 deaths). ${ }^{27}$

\section{Implications for the future}

Although the implementation of effective control measures over the last 40 years means that recent veterans are at no increased risk, the high burden of tuberculosis faced by British Service personnel up to the 1970s, when those born 1945-1949 were serving, means that there are many older veterans still living who were treated for, and/or medically discharged for, tuberculosis during their service, or who lived with latent disease throughout their service. As immune function becomes impaired in this cohort though age, disease or immunosuppressive treatment, reactivation of latent disease remains a risk and diagnosis may be more difficult owing to atypical presentation in this age group. ${ }^{28}$ Although World War II veterans were out of scope for this study, it is likely that their risk is even higher in view of the prevalence of tuberculosis, and lack of control measures, during the war years.

\section{Strengths and limitations}

The strengths of the present study are that it was based on a large cohort covering the whole of Scotland with up to 30 years' follow-up. The use of record linkage to analyse individual level data directly derived from health records allowed a robust cohort study design to be employed. The results were able to be matched or adjusted for potential confounders including deprivation. It was possible to do subgroup analysis by birth cohort, year of diagnosis and length of service, contributing to the understanding of factors influencing veterans' health.
The major limitation of the study is that although the diagnoses were taken from hospital admission and death records, and are therefore likely to be reliable in respect of those events occurring within Scotland, many cases of tuberculosis are managed in an outpatient setting, especially in more recent years. The assumption has, therefore, been made that there are no systematic differences in the likelihood of admission or death between veterans and non-veterans, other than the incidence and severity of disease, and that the relative magnitude of deaths and hospitalisations equates to the relative magnitude of total cases. Some loss to follow-up of subjects is likely to have occurred due to migration away from Scotland. Such losses could not be quantified and the assumption has been made that there was no systematic difference in this respect between veterans and non-veterans. There were no follow-up data prior to the start of linked health data collection in Scotland from 1 January 1981 . For those who are military veterans, we have not been able to link to inservice health or service records and thus tuberculosis occurring during service will not have been captured until the individual left the service and received NHS care. Because the dataset was derived from demographic, vital record and hospital admissions data, no information was available on personal lifestyle risk factors such as smoking or alcohol intake. Therefore, we were unable to directly analyse the impact of these factors or adjust for them. Veterans with Reserve service only could not be identified from NHS records and were, therefore, included among the non-veterans; this would have had the effect of reducing any observed differences between veterans and non-veterans.

\section{CONCLUSION}

Scottish veterans born before 1950 are at moderately increased risk of tuberculosis compared with age, sex and geographically matched civilians with no record of service, although the difference is not statistically significant. For those born from 1950 onwards, who served after the implementation of control measures in the Armed Forces and after the majority of those who had joined prior to the control programme had left the Services, there is a significant reduction in risk compared with civilians after adjusting for deprivation. Older veterans are at risk of reactivation of latent disease. Tuberculosis must not be overlooked in the differential diagnosis of respiratory disease in the older veteran.

Acknowledgements The authors thank the NHS Central Registry (NHSCR) and the Information Services Division, NHS Scotland (ISD) for extracting and linking the dataset.

Contributors BPB conceived the idea and designed the study, with advice from JPP and DFM. BPB carried out the data analysis, which was overseen by DFM and interpreted the findings. BPB wrote the first draft of the report, which was critically reviewed and edited by all authors. All authors approved the final article. BPB drafted the revisions and all authors approved the revised version. BPB is the guarantor.

Competing interests None declared.

Ethics approval Privacy Advisory Committee, NHS Scotland. PAC reference 27/12.

Provenance and peer review Not commissioned; externally peer reviewed.

\section{REFERENCES}

1 Atkins PJ. Milk consumption and tuberculosis in Britain, 1850-1950. In: Fenton A, ed. Order and disorder: the health implications of eating and drinking in the nineteenth and twentieth centuries. Edinburgh: Tuckwell Press, 2000:83-95.

2 Buskin SE, Gale JL, Weiss NS, et al. Tuberculosis risk factors in adults in King County, Washington, 1988 through 1990. Am J Public Health 1994;84:1750-6.

3 Pareek M, Watson JP, Ormerod LP, et al. Screening of immigrants in the UK for imported latent tuberculosis: a multicentre cohort study and cost-effectiveness analysis. Lancet Inf Dis 2011;11:435-44. 
4 Public Health England. Tuberculosis in the UK: 2014 report. London: Public Health England, 2014.

5 Lyons JG, Stewart S. Commentary: tuberculosis, diabetes and smoking: a burden greater than the sum of its parts. Int J Epidemiol 2013;42: 230-2.

6 O'Shea MK, Wilson D. Tuberculosis and the military. J R Army Med Corps 2013;159:190-9.

7 Lewthwaite CJ, Graham JT. The smoking habits of young soldiers. J R Army Med Corps 1992;138:67-71.

8 Bray I, Richardson P, Harrison K. Smoking prevalence amongst UK Armed Forces recruits: changes in behaviour after 3 years follow-up and factors affecting smoking behaviour. J R Army Med Corps 2013;159:44-50.

9 Jones E, Fear NT. Alcohol use and misuse within the military: a review. Int Rev Psychiatr 2011;23:166-72.

10 Bergman B, Miller $\mathrm{S}$. Unfit for further service: trends in medical discharge from the British Army 1861-1998. J R Army Med Corps 2000;146:204-11.

11 Stevens $H$. Tuberculosis in the armed forces and its control by BCG vaccination: a report to the research committee of the British tuberculosis association. Tubercle 1957;38:249-58.

12 NICE. Tuberculosis: clinical diagnosis and management of tuberculosis, and measures for its prevention and control. Clinical Guideline CG117. London: National Institute for Health and Care Excellence, 2001.

13 MOD. Immunological protection of entitled personnel. JSP 950 Part 1 Leaflet 7-1-1. London: Ministry of Defence, 2015.

14 Dandeker C, Wessely $\mathrm{S}$, Iversen A, et al. What's in a name? Defining and caring for "Veterans": the United Kingdom in international perspective. Armed Forces Soc 2006;32:161-77.
15 Bergman BP, Mackay DF, Pell JP. Acute myocardial infarction in Scottish military veterans: a Retrospective Cohort Study of 57,000 veterans and 173,000 matched nonveterans. Am J Epidemiol 2014;179:1434-41.

16 http://www.scotland.gov.uk/Topics/Statistics/SIMD (accessed 21 Jan 2016).

17 Grambsch PM, Therneau TM. Proportional hazards tests and diagnostics based on weighted residuals. Biometrika 1994;81:515-26.

18 Behr MA, Small PM. A historical and molecular phylogeny of BCG strains. Vaccine 1999;17:915-22

19 Anon. BCG. J R Army Med Corps 1951;96:43-5.

20 MacFarlane LRS, Jones $\mathrm{CH}$. Protection against tuberculosis of medical personnel in the Army. Tubercle 1953;34:188-91.

21 Large SE. Prevention of tuberculosis in Gurkhas. J R Army Med Corps 1965;111:131-46

22 Al-Jahdali H, Memish ZA, Menzies D. Tuberculosis in association with travel. Int J Antimicrob Agents 2003;21:125-30.

23 Hawkins NG, Davies R, Holmes TH. Evidence of psychosocial factors in the development of pulmonary tuberculosis. Am Rev Tuberc 1957;75:768-80.

24 D'Arcy M, Keane P, Clancy L. Significant life events and pulmonary tuberculosis. Irish J Psychol Med 1989;6:115-17.

25 DiStasio AJ, Trump DH. The investigation of a tuberculosis outbreak in the closed environment of a U.S. Navy ship, 1987. Mil Med 1990;155:347-51.

26 Levine VR. Epidemiology of AIDS and tuberculosis among United States Veterans. Int J Tuberc Lung Dis 1998;2:405-12.

27 Harrex WK, Horsley KW, Jelfs P, et al. Mortality of Korean War veterans; the veteran cohort study. A report of the 2002 retrospective cohort study of Australian veterans of the Korean War. Department of Veterans' Affairs Canberra, 2003.

28 Alvarez S, Shell C, Berk SL. Pulmonary tuberculosis in elderly men. Am J Med 1987;82(Part 2):602-6. 